\title{
Hypertension resistant to antihypertensive agents commonly occurs with the progression of diabetic nephropathy in Japanese patients with type 2 diabetes mellitus: a prospective observational study
}

Hiroyuki Ito ${ }^{1 *}$, Mizuo Mifune ${ }^{1}$, Mariko Abe ${ }^{1}$, Koshiro Oshikiri $^{1}$, Shinichi Antoku', Yuichiro Takeuchi ${ }^{1}$, Michiko Togane ${ }^{1}$, Shigenori Ando ${ }^{2}$ and Emiko Tsugami²

\begin{abstract}
Background: We investigated 1) the frequency of hypertension in patients with type 2 diabetes graded by the new classification of chronic kidney disease (CKD) reported by the Kidney Disease: Improving Global Outcomes (KDIGO) and 2) the number of antihypertensive agents needed to achieve treatment goals using a prospective observational study.
\end{abstract}

Methods: A population of 2018 patients with type 2 diabetes mellitus was recruited for the study. The CKD stage was classified according to the eGFR and the urinary albumin excretion levels.

Results: Hypertension was found in 1420 (70\%) of the patients, and the proportion of subjects showing a blood pressure $<130 / 80 \mathrm{mmHg}$ was $31 \%$ at the baseline. Although the mean blood pressure was approximately 130/ $75 \mathrm{mmHg}$, the rate of patients with a blood pressure of $<130 / 80 \mathrm{mmHg}$ became limited to $41-50 \%$ during the observation period. The number of antihypertensive agents required for treatment was significantly higher at the endpoint $(2.0 \pm 1.3)$ than at the baseline (1.6 \pm 1.2$)$. Furthermore, it increased with the progression of the CKD stage at both the baseline and the endpoint of the observation. However, the frequency of subjects who did not achieve the blood pressure target was found to increase in the group demonstrating the later stage of CKD.

Conclusions: Hypertension resistant to antihypertensive agents was common in the patients with type 2 diabetes mellitus and increased with the progression of CKD. Although powerful combination therapy using antihypertensive agents is considered necessary for the strict control of blood pressure, this became difficult in individuals who were in advanced stages as graded based on the eGFR and the urinary albumin excretion levels.

Keywords: Hypertension, Antihypertensive agents, Chronic kidney disease, CKD stage, Type 2 diabetes mellitus, KDIGO

\footnotetext{
* Correspondence: ito@edogawa.or.jp

'Department of Diabetes, Metabolism and Kidney Disease, Edogawa Hospital,

2-24-18, Higashi-Koiwa, Edogawa, Tokyo 133-0052, Japan

Full list of author information is available at the end of the article
} 


\section{Background}

It is well-known that hypertension is common in the patients with type 2 diabetes mellitus [1,2]. Hypertension is a major risk factor for the onset and progression of diabetic micro-a and macrovascular complications, as well as hyperglycemia [3,4]. Furthermore, the risk for cardiovascular events synergistically increases in the patients with both diabetes mellitus and hypertension [5]. The target blood pressure is recommended to be less than $130 / 80 \mathrm{mmHg}$ in order to prevent diabetic vascular events [6,7]. Although it was reported that angiotensinconverting enzyme inhibitors (ACEIs) and angiotensin II receptor blockers (ARBs) have vascular protective effects, especially in the patients with diabetic nephropathy [8-13], it is often difficult to control blood pressure using single agents, and combination therapy was needed in many diabetic patients with hypertension [14].

The frequency of hypertension is elevated with the progression of renal damage in both diabetic and nondiabetic patients. In the present prospective observational study, we investigated 1) the frequency of hypertension in the patients with type 2 diabetes as graded by the new classification of chronic kidney disease (CKD) reported by the Kidney Disease: Improving Global Outcomes (KDIGO) [15] and 2) the number of antihypertensive agents needed to achieve the treatment goals.

\section{Methods}

\section{Ethics statement}

This study was conducted according to the principles expressed in the Declaration of Helsinki. The Ethics Committees of Edogawa Hospital approved the protocol of this study and waived the need for written informed consent because the data were analyzed anonymously for this observation study based on the data stored in the hospital database.

\section{Study population and methods}

A population of 2018 patients diagnosed with type 2 diabetes mellitus who underwent consecutive evaluations, including blood pressure, urinalysis and determination of the serum creatinine levels in the Department of Diabetes, Metabolism and Kidney Disease of Edogawa Hospital, Tokyo, Japan between April 2008 and March 2011 was recruited for the study. Antihypertensive agents were essentially initiated when a systolic blood pressure $(\mathrm{SBP}) \geq 130 \mathrm{mmHg}$ and/or a diastolic blood pressure $(\mathrm{DBP}) \geq 80 \mathrm{mmHg}$ persisted after the lifestyle modification. The selection of antihypertensive agents was determined by each patient's physician during the prospective observation period.

The blood pressure was measured twice with the subjects in the sitting position after a 5 minute rest. The lower value of the two measurements was used for the study. Hypertension was defined as a SBP $\geq 140 \mathrm{mmHg}$ and/or a DBP $\geq 90 \mathrm{mmHg}$. The participants currently using antihypertensive medications were also classified as positive for hypertension. The target blood pressure is less than $130 / 80 \mathrm{mmHg}$ according to the JNC7 [6] and the guidelines proposed by the European Society of Hypertension and of the European Society of Cardiology [8].

The patients were divided into four groups according to their blood pressure status. Categories 1, 2, 3 and 4 were defined to be the subjects showing 1) $\mathrm{SBP}<130 \mathrm{mmHg}$ and $\mathrm{DBP}<80 \mathrm{mmHg}, 2) \mathrm{SBP}<130 \mathrm{mmHg}$ and $\mathrm{DBP} \geq$ $80 \mathrm{mmHg}$, 3) SBP $\geq 130 \mathrm{mmHg}$ and $\mathrm{DBP}<80 \mathrm{mmHg}$, and 4) $\mathrm{SBP} \geq 130$ and $\mathrm{DBP} \geq 80 \mathrm{mmHg}$, respectively. The doses and specific drug classes of antihypertensive agents for blood pressure control were dependent on the judgment of each patient's physician.

The number of antihypertensive agents used was expressed as the sum of antihypertensive agents such as thiazide diuretics, loop diuretics, aldosterone antagonists, alpha blockers, beta blockers, calcium channel blockers (CCBs), ACEIs, ARBs, renin inhibitors, and centrally-acting adrenergic drugs being used.

The estimated glomerular filtration rate (eGFR) was calculated using the formula reported by Matsuo et al. [16]. This equation originated from the MDRD study group [17] arranged for Japanese individuals, and it is recommended by the Japanese Society of Nephrology: eGFR $\left(\mathrm{mL} / \mathrm{min} / 1.73 \mathrm{~m}^{2}\right)=194 \times \mathrm{Scr}^{-1.094} \times \mathrm{Age}^{-0.287} \times 0.739$ (if female).

The CKD stage was classified according to the eGFR and the urinary albumin excretion (UAE). The GFR stage was graded as: G1, eGFR $\geq 90 \mathrm{~mL} / \mathrm{min} / 1.73 \mathrm{~m}^{2}$; $\mathrm{G} 2,90 \mathrm{~mL} / \mathrm{min} / 1.73 \mathrm{~m}^{2}>\mathrm{eGFR} \geq 60 \mathrm{~mL} / \mathrm{min} / 1.73 \mathrm{~m}^{2}$; G3a, $60 \mathrm{~mL} / \mathrm{min} / 1.73 \mathrm{~m}^{2}>\mathrm{eGFR} \geq 45 \mathrm{~mL} / \mathrm{min} / 1.73 \mathrm{~m}^{2}$; G3b, $45 \mathrm{~mL} / \mathrm{min} / 1.73 \mathrm{~m}^{2}>$ eGFR $\geq 30 \mathrm{~mL} / \mathrm{min} / 1.73 \mathrm{~m}^{2}$; G4, $30 \mathrm{~mL} / \mathrm{min} / 1.73 \mathrm{~m}^{2}>$ eGFR $\geq 15 \mathrm{~mL} / \mathrm{min} / 1.73 \mathrm{~m}^{2}$; and $\mathrm{G} 5,15 \mathrm{~mL} / \mathrm{min} / 1.73 \mathrm{~m}^{2}>$ eGFR [15]. The UAE is presented as the albumin-to-creatinine ratio (ACR; $\mathrm{mg} / \mathrm{g}$ creatinine). The albuminuria stage was graded according to an analysis of a spot urine sample as: A1 (normoalbuminuria), ACR $<30 \mathrm{mg} / \mathrm{g}$ creatinine; A2 (microalbuminuria), $30 \leq \mathrm{ACR}<300 \mathrm{mg} / \mathrm{g}$ creatinine; or A3 (macroalbuminuria), ACR $\geq 300 \mathrm{mg} / \mathrm{g}$ creatinine (or dipstick urinalysis revealing $2+, 3+$ or $4+$ ).

The HbA1c levels were determined by a high performance liquid chromatography method using an automated HLC-723 G7 analyzer (Tosoh Corporation, Tokyo, Japan) and calibrated by the Japan Diabetes Society (JDS) standard calibrators. The value for HbA1c (\%) was estimated as a National Glycohemoglobin Standardization Program (NGSP) equivalent value (\%) calculated by the formula: HbA1c $=\mathrm{HbA1c}($ JDS $)+0.4$, considering the relational expression of HbA1c (JDS) 
measured by the previous Japanese standard substance and the measurement methods and HbA1c (NGSP) [18].

\section{Statistical methods}

All data are shown as the means \pm SD. An analysis of variance (ANOVA) and the $\chi^{2}$ test were used for between-group comparisons of the continuous and categorical variables, respectively. A paired- $t$ test was performed to determine the significance of the change in the number of antihypertensive agents. Differences of $P<0.05$ (two-tailed) were considered to be statistically significant. The statistical software package JMP, version 8.0 (SAS Institute, Cary, NC, USA), was used to perform all of the analyses.

\section{Results}

Table 1 shows the baseline clinical characteristics and the laboratory parameters of the patients. Hypertension was found in 1420 (70\%) patients, and $31 \%$ of the

Table 1 The baseline clinical characteristics of the patients

\begin{tabular}{|c|c|c|}
\hline & $\% /$ Mean \pm SD & $\begin{array}{l}\text { Number } \\
\text { estimated (\%) }\end{array}$ \\
\hline Age (years) & $63 \pm 12$ & $2018(100)$ \\
\hline Men & 62 & $2018(100)$ \\
\hline Duration of diabetes mellitus (years) & $9.4 \pm 9.8$ & $1723(85)$ \\
\hline Current plus past smoking & 59 & 1585 (79) \\
\hline Drinkers \# & 42 & 1671 (83) \\
\hline Treatment for diabetes mellitus & & $2018(100)$ \\
\hline Diet only/OHA/insulin/GLP-1 analogue & $17 / 56 / 27 / 0$ & \\
\hline Body mass index $\left(\mathrm{kg} / \mathrm{m}^{2}\right)$ & $24.9 \pm 4.3$ & 1995 (99) \\
\hline Obesity \#\# & 44 & 1995 (99) \\
\hline Systolic blood pressure (mmHg) & $139 \pm 21$ & $2018(100)$ \\
\hline Diastolic blood pressure $(\mathrm{mmHg})$ & $80 \pm 14$ & $2018(100)$ \\
\hline Hypertension & 70 & $2018(100)$ \\
\hline Number of antihypertensive agents & $1.6 \pm 1.2$ & $1420(70)$ \\
\hline Control of blood pressure & & $2018(100)$ \\
\hline Category 1 & 31 & 629 \\
\hline Category 2 & 4 & 90 \\
\hline Category 3 & 20 & 407 \\
\hline Category 4 & 44 & 892 \\
\hline HbA1c (\%) & $8.5 \pm 2.2$ & $1887(94)$ \\
\hline Glycoalbumin (\%) & $24.7 \pm 8.4$ & $206(10)$ \\
\hline Estimated GFR (mL/min/1.73 m²) & $55 \pm 20$ & $2018(100)$ \\
\hline
\end{tabular}

$\mathrm{OHA}$ : oral hypoglycemic agents, GFR: glomerular filtration rate.

\# Drinkers were defined as those who consumed more than $20 \mathrm{~g} /$ day of ethanol.

\#\# Obesity was considered to be present in individuals with a body mass index $\geq 25 \mathrm{~kg} / \mathrm{m}^{2}$. subjects showed a blood pressure $<130 / 80 \mathrm{mmHg}$. No antihypertensive agent was administered to 259 patients with hypertension. The number of antihypertensive agents used was 1, 2, 3, 4, 5, 6 and 7 in 471, 403, 196, 63, 21, 6 and 1 patients, respectively. The mean number of antihypertensive agents being used by the patients with hypertension and diabetes was 1.6.

The distribution of the patients divided by their albuminuria stage and GFR stage is shown in Table 2. The frequency of hypertension was significantly increased with the progression of the albuminuria stage $(P<0.01)$ and the GFR stage $(P<0.01)$ (Figure 1$)$.

Figure 2-A shows the blood pressure during the observation period in all subjects. Although the mean blood pressure was improved $(132 / 75 \mathrm{mmHg}, 131 / 75 \mathrm{mmHg}$, $129 / 73 \mathrm{mmHg}$ and $130 / 68 \mathrm{mmHg}$ at 12, 24, 26 and 48 months, respectively), the rate of patients who were in category 1 (SBP $<130 \mathrm{mmHg}$ and $\mathrm{DBP}<80 \mathrm{mmHg}$ ) was limited to $41-50 \%$ of the patients (Figure 2-B). In the 1359 patients who were observed for more than 12 months, the final blood pressure was $131 \pm 16 / 74 \pm 12 \mathrm{mmHg}$, and the rate of patients in category 1 was $43 \%$. The percentages of individuals who did not achieve the target blood pressure (Categories $2+3+4$ ) were decreased at the endpoint of the observation compared with the baseline (Figure 3). They percentage increased in the subjects demonstrating later stage of the albuminuria $(P<0.01)$ and the GFR $(P<0.01)$ at the endpoint of the observation (Figure 3-B).

Table 2 shows a comparison of the number of antihypertensive agents used in the patients with hypertension and diabetes at the baseline $(n=1420)$ and at the endpoint of the observation for more than 12 months $(n=990)$. The number of antihypertensive agents was significantly higher at the endpoint than at the baseline. Furthermore, it increased with the progression of CKD stage at both the baseline and the endpoint of the observation period.

CCBs, ACEIs, ARBs and thiazide diuretics were used by $52 \%, 15 \%, 55 \%$ and $13 \%$ of the patients at the baseline, and by $64 \%, 23 \%, 65 \%$ and $7 \%$ at the endpoint of the observation period.

\section{Discussion}

In the present study, a much higher frequency of hypertension was found in the patients with type 2 diabetes mellitus. It could be argued that this is because our study included a number of CKD patients, although our results were consist with previous reports that showed hypertension to be frequently complicated with diabetes $[1,2]$. Our investigation is the first report showing that the frequency of hypertension was elevated with the progression of CKD, and that more drugs were needed for the treatment of hypertension during the progression of CKD. Furthermore, the percentage of patients who 
Table 2 The number of antihypertensive agents used in the patients with hypertension and diabetes at the baseline and at the endpoint of the observation

\begin{tabular}{|c|c|c|c|c|c|c|c|c|}
\hline \multirow[b]{3}{*}{ GFR stage } & \multicolumn{6}{|c|}{ Albuminuria stage } & & \\
\hline & \multicolumn{2}{|c|}{ A1 } & \multicolumn{2}{|c|}{$\mathrm{A} 2$} & \multicolumn{2}{|c|}{ A3 } & \multicolumn{2}{|c|}{ Average } \\
\hline & Baseline $\$$ & Endpoint $^{5}$ & Baseline $^{\$}$ & Endpoint $^{5}$ & Baseline $^{\$}$ & Endpoint $^{5}$ & Baseline $^{\$}$ & Endpoint $^{\$}$ \\
\hline $\mathrm{G} 1+\mathrm{G} 2$ & $1.3 \pm 1.0$ & $1.7 \pm 1.0$ & $1.1 \pm 1.0$ & $1.7 \pm 1.0$ & $1.2 \pm 0.8$ & $2.0 \pm 0.9^{\$ \S}$ & $1.2 \pm 1.0$ & $1.7 \pm 1.0$ \\
\hline$n(\%$ of all) & $261(18.3)$ & $182(18.4)$ & $127(8.9)$ & $79(8.0)$ & $58(4.1)$ & $37(3.7)$ & $446(31.4)$ & $298(40)$ \\
\hline $\mathrm{G} \mathrm{a}^{\#}$ & $1.4 \pm 1.0$ & $1.7 \pm 1.0$ & $1.4 \pm 1.1$ & $1.8 \pm 1.2$ & $1.5 \pm 0.9$ & $2.3 \pm 1.2$ & $1.4 \pm 1.0$ & $1.8 \pm 1.1$ \\
\hline$n$ (\% of all) & $269(18.9)$ & $217(21.9)$ & $140(9.9)$ & $82(8.3)$ & $86(6.1)$ & $68(6.9)$ & $495(34.9)$ & $367(37.1)$ \\
\hline $\mathrm{G} \mathrm{b}^{\#}$ & $1.9 \pm 1.1$ & $2.1 \pm 1.2$ & $1.5 \pm 1.3$ & $2.0 \pm 1.1$ & $2.0 \pm 1.3$ & $2.6 \pm 1.4$ & $1.9 \pm 1.3$ & $2.3 \pm 1.3^{*}$ \\
\hline$n(\%$ of all) & $123(8.7)$ & $93(9.4)$ & $63(4.4)$ & $40(4.0)$ & $106(7.5)$ & $79(8.0)$ & $292(20.6)$ & $212(21.4)$ \\
\hline $\mathrm{G} 4+\mathrm{G} 5$ & $3.0 \pm 1.6$ & $3.2 \pm 1.8$ & $2.4 \pm 1.6$ & $2.6 \pm 1.2$ & $2.5 \pm 1.3$ & $2.9 \pm 1.4$ & $2.5 \pm 1.4$ & $2.9 \pm 1.4$ \\
\hline$n$ (\% of all) & $10(1.0)$ & $6(0.9)$ & $22(1.5)$ & $8(0.8)$ & $155(10.9)$ & $99(10)$ & $187(13.2)$ & $113(11.4)$ \\
\hline Average $^{* \#}$ & $1.5 \pm 1.1$ & $1.8 \pm 1.1$ & $1.4 \pm 1.2$ & $1.8 \pm 1.1$ & $2.0 \pm 1.3$ & $2.5 \pm 1.4$ & $1.6 \pm 1.2$ & $2.0 \pm 1.3$ \\
\hline$n$ (\% of all) & $663(46.7)$ & $498(50.3)$ & $352(24.8)$ & $209(21.1)$ & 405 (28.5) & $283(28.6)$ & $1420(100)$ & $990(100)$ \\
\hline
\end{tabular}

${ }^{*} P<0.01$ among $A 1, A 2$ and $A 3$ at baseline and ${ }^{\#} P<0.01$ among $A 1, A 2$ and $A 3$ at endpoint.

$\$ P<0.01$ among $\mathrm{G} 1+\mathrm{G} 2, \mathrm{G} 2, \mathrm{G} 3$ and $\mathrm{G} 4+\mathrm{G} 5$.

achieved the blood pressure target decreased in those demonstrating the later stage of CKD, despite their increased use of antihypertensive agents.

Bakris et al. reviewed the various clinical trials for either diabetes or renal impairment. An average of 3.2 different antihypertensive medications was taken daily in the UKPDS [3], ABCD [19], MDRD [20], HOT [21] and AASK [22] trials, even though the average blood pressure in these patients was slightly less than 140/ $90 \mathrm{mmHg}$ [14]. The mean blood pressure of our study reached approximately $130 / 75 \mathrm{mmHg}$ at the endpoint of observation using fewer drugs. The differences were considered to be caused by the use of more recent antihypertensive agents, such as long-acting CCBs and ARBs. Because the essential antihypertensive agents were thiazide diuretics, beta blockers, CCBs and/or ACEIs in these previous investigations, it is difficult to make a simple comparison to the present study.

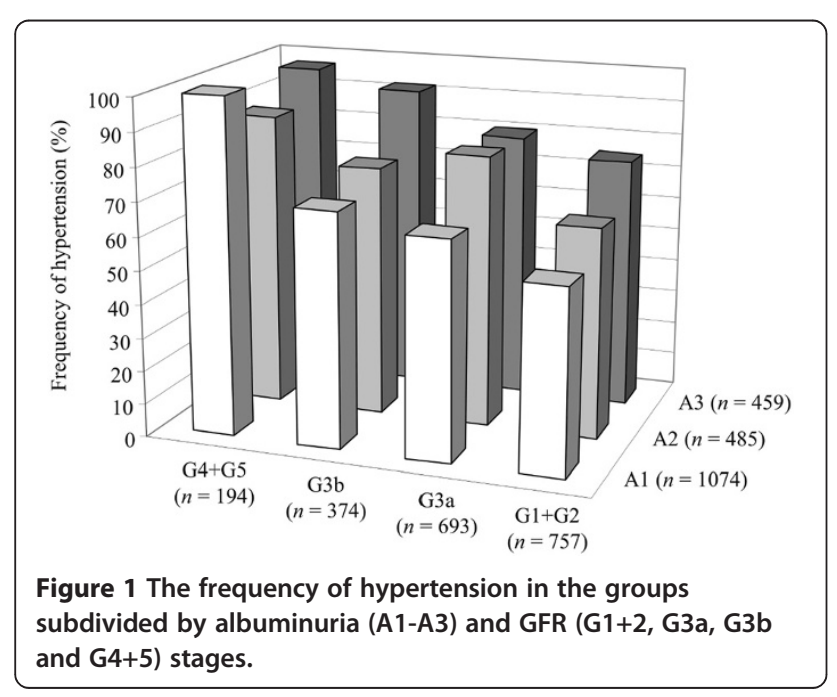

The target value of blood pressure has continued to decline after the JNC I [23] was published as the first guideline for the treatment of hypertension in 1977. As strict control is required, especially in diabetic patients, we also tried to keep the blood pressure less than 130/ $80 \mathrm{mmHg}$ in the present study. However, our current treatment protocol was considered to be insufficient for blood pressure control in patients with type 2 diabetes, even when a combination using two or more antihypertensive drugs was administered (the subjects who met the treatment goal comprised only $\sim 50 \%$ of the population at the endpoint). Furthermore, tight control became more difficult as the CKD stage progressed.

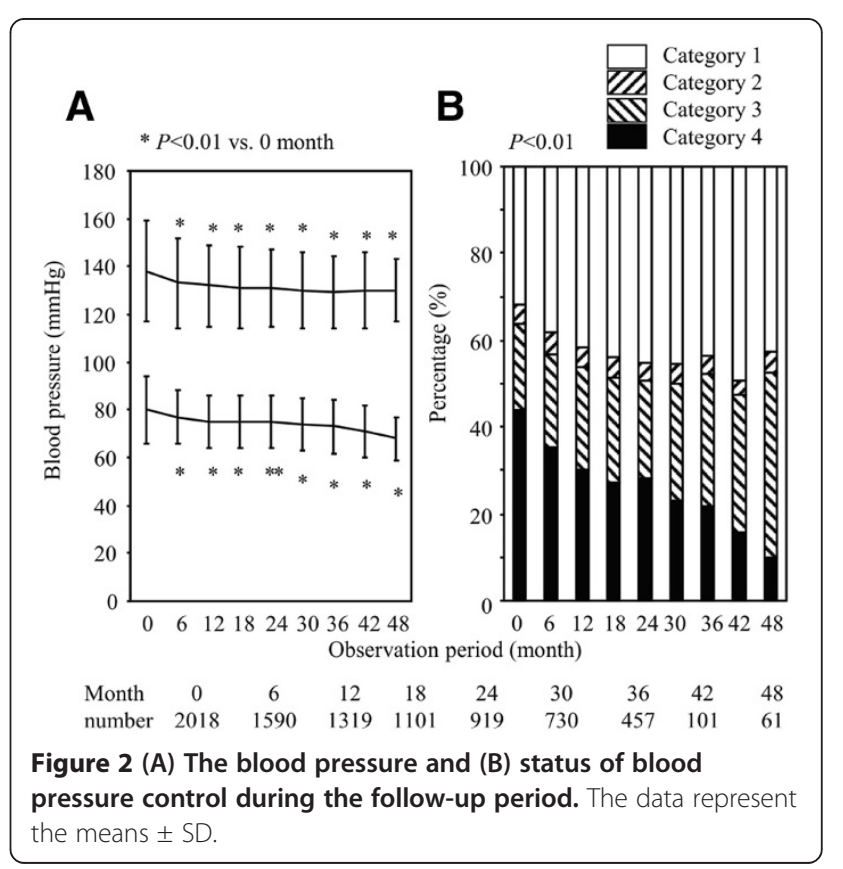



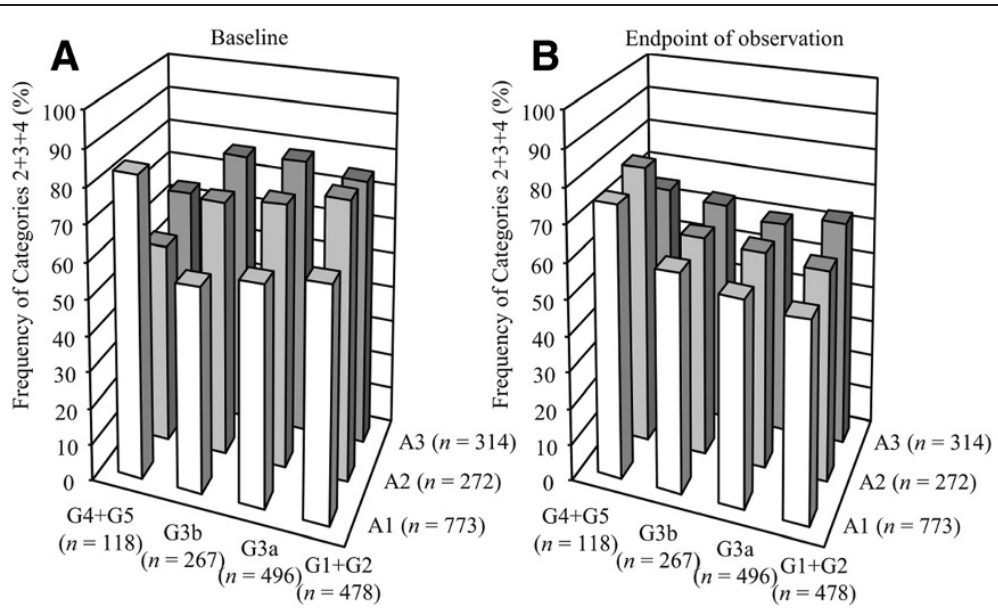

Figure 3 The percentages of individuals who did not achieve the target blood pressure (Categories $2+3+4)$ among the patients with different CKD stages at the baseline (A) and at the endpoint of observation (B) in the total of 1359 patients who were observed for more than 12 months.

Unlike previous clinical studies, we are currently able to use various antihypertensive agents showing more powerful effects such as can be achieved using longacting CCBs, ACEIs, ARBs and renin inhibitors. More aggressive treatment strategies, including some combination tablets, are therefore desirable in addition to the lifestyle modifications, in order to increase the likelihood that the target blood pressure can be reached and maintained.

Therapeutic resistance to antihypertensive agents in the late stage of CKD with diabetes mellitus is considered to be caused some defective mechanisms of vascular homeostasis and impaired nitric oxide production [24]. Vascular repair, according to a renal hemodynamic study [25], and nitric oxide production from the renal endothelial cells [26], have both been reported to be adequately functional in patients with the early stage of diabetic nephropathy. However, the number of antihypertensive agents had been higher during the entire observation period, even in the early stage $(\mathrm{G} 1+\mathrm{G} 2$ and A1) of diabetic nephropathy, in the present study. This is thought to be due to the insufficient number of antihypertensive agents $(1.3 \pm 1.0)$ taken at the baseline by the G1 + G2/A1 stage patients.

The present study has several important limitations. First, the follow-up period was relatively short, and the number of patients decreased to nearly one-half at 24 months and to one-fourth at 36 months. This might have led us to incorrectly estimate the blood pressure control and the number of antihypertensive agents required for control. Second, we did not determine the dose of antihypertensive agents required. The doses administered were dependent on the judgment of each patient's physician, as was the decision to add another antihypertensive agent or increase the dose of a drug that was already being used. When the dose increases, the enhanced antihypertensive therapy is not reflected in the number of antihypertensive agents. Third, the blood pressure measured at home was not evaluated in this study. If self-monitoring of blood pressure shows good control for hypertension, then physicians will not increase the therapy, even if the office blood pressure does not meet the target goal levels. This is considered to be one of the reasons why more than half of the patients remained within categories 2-4 in the present study. Fourth, the lower value of two measurements of blood pressure was used for this study, not the average value, which is recommended by the National Institutes of Health [6] and the Japanese Society of Hypertension [27]. This might have led to the underestimation of the blood pressure level observed in this investigation. Fifth, the number of patients gradually decreased during the observation period. It was possible that the omission of individuals with higher blood pressure had thus caused the improvement in the blood pressure that was seen during the observation period.

\section{Conclusion}

In conclusion, hypertension was common in patient with type 2 diabetes mellitus and increased with the progression of CKD. Although powerful combination therapy using antihypertensive agents is considered to be necessary for the strict control of blood pressure, it becomes more difficult for individuals in the progressive stages of CKD as determined based on the albuminuria and GFR levels.

\section{Competing interests}

The author(s) declare that they have no competing interests. 


\section{Authors' contributions}

$\mathrm{HI}$ contributed to the conception and design of the study, research, analysis and interpretation of data, and the drafting of the manuscript. MM, MA, KO, $S A, Y T, M T, S A$ and ET contributed to the research and interpretation of the data, and to the critical revision of the manuscript. All authors have given their final approval of the submitted version of the manuscript. All authors read and approved the final manuscript.

\section{Acknowledgements}

The authors thank Ms. Tomoko Koyanagi of the secretarial section of Edogawa Hospital for her valuable help in the data collection.

\section{Author details}

'Department of Diabetes, Metabolism and Kidney Disease, Edogawa Hospital, 2-24-18, Higashi-Koiwa, Edogawa, Tokyo 133-0052, Japan. ${ }^{2}$ Pharmaceutical Department, Edogawa Hospital, 2-24-18, Higashi-Koiwa, Edogawa, Tokyo 133-0052, Japan

Received: 23 January 2012 Accepted: 27 June 2012

Published: 27 June 2012

\section{References}

1. Kannel WB: Risk factors in hypertension. J Cardiovasc Pharmacol 1989, 13 (Suppl 1):S4-S10.

2. limura O: Insulin resistance and hypertension in Japanese. Hypertens Res 1996, 19(Suppl 1):S1-S8.

3. UK Prospective Diabetes Study Group: Tight blood pressure control and risk of macrovascular and microvascular complications in type 2 diabetes: UKPDS 38. BMJ 1998, 317:703-713.

4. Holman RR, Paul SK, Bethel MA, Matthews DR, Neil HA: 10-year follow-up of intensive glucose control in type 2 diabetes. N Engl J Med 2008, 359:1577-1589

5. American Diabetes Association: Role of cardiovascular risk factors in prevention and treatment of macrovascular disease in diabetes. Diabetes Care 1989, 12:573-579.

6. Chobanian AV, Bakris GL, Black HR, Cushman WC, Green LA, Izzo JL Jr, Jones DW, Materson BJ, Oparil S, Wright JT Jr, Roccella EJ, Joint National Committee on Prevention, Detection, Evaluation, and Treatment of High Blood Pressure. National Heart, Lung, and Blood Institute; National High Blood Pressure Education Program Coordinating Committee: Seventh report of the Joint National Committee on Prevention, Detection, Evaluation, and Treatment of High Blood Pressure. Hypertension 2003, 42:1206-1252.

7. Mancia G, De Backer G, Dominiczak A, Cifkova R, Fagard R, Germano G, Grassi G, Heagerty AM, Kjeldsen SE, Laurent S, Narkiewicz K, Ruilope L, Rynkiewicz A, Schmieder RE, Boudier HA, Zanchetti A, ESH-ESC Task Force on the Management of Arterial Hypertension: Management of Arterial Hypertension of the European Society of Hypertension; European Society of Cardiology. 2007 Guidelines for the Management of Arterial Hypertension: The Task Force for the Management of Arterial Hypertension of the European Society of Hypertension (ESH) and of the European Society of Cardiology (ESC). J Hypertens 2007, 2007(25):1105-1187.

8. Heart Outcomes Prevention Evaluation Study Investigators: Effects of ramipril on cardiovascular and microvascular outcomes in people with diabetes mellitus: results of the HOPE study and MICRO-HOPE substudy. Lancet 2000, 55:253-259.

9. Lewis EJ, Hunsicker LG, Bain RP, Rohde RD, The Collaborative Study Group: The effect of angiotensin-converting-enzyme inhibition on diabetic nephropathy. N Engl J Med 1993, 329:1456-1462.

10. Brenner BM, Cooper ME, de Zeeuw D, Keane WF, Mitch WE, Parving HH, Remuzzi G, Snapinn SM, Zhang Z, Shahinfar S; RENAAL Study Investigators: Effects of losartan on renal and cardiovascular outcomes in patients with type 2 diabetes and nephropathy. N Engl J Med 2001, 345:861-869.

11. Lewis EJ, Hunsicker LG, Clarke WR, Berl T, Pohl MA, Lewis JB, Ritz E, Atkins RC, Rohde R, Raz I, Collaborative Study Group: Renoprotective effect of the angiotensin-receptor antagonist irbesartan in patients with nephropathy due to type 2 diabetes. N Engl J Med 2001, 345:851-860.

12. Parving HH, Lehnert $H$, Bröchner-Mortensen J, Gomis R, Andersen S, Arner P, Irbesartan in Patients with Type 2 Diabetes and Microalbuminuria Study Group: The effect of irbesartan on the development of diabetic nephropathy in patients with type 2 diabetes. N Engl J Med 2001 345:870-878.
13. Viberti G, Wheeldon NM, MicroAlbuminuria Reduction With VALsartan (MARVAL) Study Investigators: Microalbuminuria reduction with valsartan in patients with type 2 diabetes mellitus: a blood pressure-independent effect. Circulation 2002, 106:672-678.

14. Bakris GL, Williams M, Dworkin L, Elliott WJ, Epstein M, Toto R, Tuttle K, Douglas J, Hsueh W, Sowers J: Preserving renal function in adults with hypertension and diabetes: a consensus approach. Am J Kidney Dis 2000, 36:646-661.

15. Levey AS, de Jong PE, Coresh J, El Nahas M, Astor BC, Matsushita K, Gansevoort RT, Kasiske BL, Eckardt KU: The definition, classification, and prognosis of chronic kidney disease: a KDIGO Controversies Conference report. Kidney Int 2011, 80:17-28.

16. Matsuo S, Imai E, Horio M, Yasuda Y, Tomita K, Nitta K, Yamagata K, Tomino $Y$, Yokoyama $H$, Hishida A, Collaborators developing the Japanese equation for estimated GFR: Revised equations for estimated GFR from serum creatinine in Japan. Am J Kidney Dis 2009, 53:982-992.

17. Coresh J, Astor BC, Greene T, Eknoyan G, Levey AS: Prevalence of chronic kidney disease and decreased kidney function in the adult US population: Third National Health and Nutrition Examination Survey. Am J Kidney Dis 2003, 41:1-12.

18. Seino Y, Nanjo K, Tajima N, Kadowaki T, Kashiwagi A, Araki E, Ito C, Inagaki N, Iwamoto Y, Kasuga M, Hanafusa T, Haneda M, The Committee of the Japan Diabetes Society on the Diagnostic Criteria of Diabetes Mellitus: Report of the Committee on the Classification and Diagnostic Criteria of Diabetes Mellitus. J Diabetes Invest 2010, 1:213-228.

19. Estacio RO, Jeffers BW, Hiatt WR, Biggerstaff SL, Gifford N, Schrier RW: The effect of nisoldipine as compared with enalapril on cardiovascular outcomes in patients with non-insulin-dependent diabetes and hypertension. N Engl J Med 1998, 338:645-652.

20. Peterson JC, Adler S, Burkart JM, Greene T, Hebert LA, Hunsicker LG, King AJ, Klahr S, Massry SG, Seifter JL: Blood pressure control, proteinuria, and the progression of renal disease. The Modification of Diet in Renal Disease Study. Ann Intern Med 1995, 123:754-762.

21. Hansson L, Zanchetti A, Carruthers SG, Dahlöf B, Elmfeldt D, Julius S, Ménard J, Rahn KH, Wedel H, Westerling S: Effects of intensive blood-pressure lowering and low-dose aspirin in patients with hypertension: principal results of the Hypertension Optimal Treatment (HOT) randomized trial. HOT Study Group. Lancet 1998, 351:1755-1762.

22. Wright JT Jr, Bakris G, Greene T, Agodoa LY, Appel L, Charleston J, Cheek D, Douglas-Baltimore JG, Gassman J, Glassock R, Hebert L, Jamerson K, Lewis J, Phillips RA, Toto RD, Middleton JP, Rostand SG, African American Study of Kidney Disease and Hypertension Study Group: Effect of blood pressure lowering and antihypertensive drug class on progression of hypertensive kidney disease: results from the AASK trial. JAMA 2002, 288:2421-2431.

23. Joint National Committee: Report of the Joint National Committee on Detection, Evaluation, and Treatment of High Blood Pressure. A cooperative study. JAMA 1977, 237:255-261.

24. Futrakul N, Futrakul P: Vascular homeostasis and angiogenesis determine therapeutic effectiveness in type 2 diabetes. Int J Vasc Med 2011, 2011:971524.

25. Futrakul N, Kulaputana O, Futrakul P, Chavanakul A, Deekajorndech T: Enhanced peritubular capillary flow and renal function can be accomplished in normoalbuminuric type 2 diabetic nephropathy. Ren Fail 2011, 33:312-315.

26. Ritt M, Ott C, Raff U, Schneider MP, Schuster I, Hilgers KF, Schlaich MP, Schmieder RE: Renal vascular endothelial function in hypertensive patients with type 2 diabetes mellitus. Am J Kidney Dis 2009, 53:281-289.

27. Ogihara T, Kikuchi K, Matsuoka H, Fujita T, Higaki J, Horiuchi M, Imai Y, Imaizumi T, Ito S, Iwao H, Kario K, Kawano Y, Kim-Mitsuyama S, Kimura G, Matsubara H, Matsuura H, Naruse M, Saito I, Shimada K, Shimamoto K, Suzuki H, Takishita S, Tanahashi N, Tsuchihashi T, Uchiyama M, Ueda S, Ueshima H, Umemura S, Ishimitsu T, Rakugi H, Japanese Society of Hypertension Committee: The Japanese Society of Hypertension Guidelines for the Management of Hypertension (JSH 2009). Hypertens Res 2009, 32:3-107.

\section{doi:10.1186/1471-2369-13-48}

Cite this article as: Ito et al:: Hypertension resistant to antihypertensive agents commonly occurs with the progression of diabetic nephropathy in Japanese patients with type 2 diabetes mellitus: a prospective observational study BMC Nephrology 2012 13:48 